Research Article

\title{
Big Data-IoT: An Analysis of Multidimensional Proximity Implications on Green Innovation Performance-An Empirical Study of the Data from the Chinese Power Industry
}

\author{
Xiao Zhenhong, ${ }^{1}$ Tan Rui $\mathbb{D}^{1,2}$ Shi Jianbang, ${ }^{1}$ Luo Xiaomei, ${ }^{3}$ Wang Fang, ${ }^{3}$ and An Rui ${ }^{3}$ \\ ${ }^{1}$ School of Economics and Management, Harbin Engineering University, Harbin, Heilongjiang 150001, China \\ ${ }^{2}$ School of Continuing Education, Beijing University of Technology, Beijing 100024, China \\ ${ }^{3}$ School of Economics and Management, Beijing University of Technology, Beijing 100024, China
}

Correspondence should be addressed to Tan Rui; tanrui@bjut.edu.cn

Received 10 May 2021; Revised 21 June 2021; Accepted 26 June 2021; Published 3 July 2021

Academic Editor: Fazlullah Khan

Copyright (c) 2021 Xiao Zhenhong et al. This is an open access article distributed under the Creative Commons Attribution License, which permits unrestricted use, distribution, and reproduction in any medium, provided the original work is properly cited.

\begin{abstract}
With the global energy crisis and environmental degradation getting more rigorous, an essential approach is required to attain introverted development through structural optimization, autonomous invention, and technological innovation system. It is an important way to include energy conservation, emission reductions, and the implementation of a low-carbon mode in the power industry, which is a highly polluting sector of the national economy. This article is based on the State Intellectual Property Office of China's patent search and analysis database. We choose the number of green patents jointly submitted for innovative topics in the power industry from 2016 to 2020 . The negative binomial regression is constructed from the standpoint of multidimensional closeness by employing Gephi visual analysis, Ucinet, and the Stata 15 regional model. Furthermore, we investigate the impact of geographical closeness, technological closeness, and institutional closeness, as well as their interaction, on the green innovation performance of inventive organizations in China's power industry. According to the findings of the study, geographical and institutional closeness have an important influence in increasing the green innovation performance. The suggested model applies to the power sector, and technological closeness has an inverted $U$-shaped association with green innovation performance in the power business. Furthermore, the model output at inference time is just a collection of successive parameters that improve the interaction of the closeness of innovation subjects to the green innovation performance of the power industry, all of which are represented as complementary effects.
\end{abstract}

\section{Introduction}

With the ongoing review of Chinese mechanical creative development, China's logical and mechanical progress has increased to $59.5 \%$, and China has achieved the 17 th position in the world. China's energy organizations grew rapidly, as a result of the "weighty obligation and high impact" criteria. With the expansion of industrial innovations, new energy efforts have expanded swiftly, such as wind power, hydropower, photovoltaic force age, etc. Similarly, ideas for the Ubiquitous Electric Web of Things and microgrid arise regularly with the growth of breakthroughs like $5 \mathrm{G}$ and the Internet of Things (IoT). The review of the Chinese energy industry in 2020s existing situation and improving prospects shows that China's energy sector mainly has five forwardlooking benchmarks. These include digitization, cleaning, simplicity, globalization, and jolt, which would be the central theme of the progress later in the Chinese power industries in digitization and cleaning. However, the power industry is experiencing increasingly severe international competition as a heavily polluting sector in the national economy. This is because of the growing global energy shortage, increased pollution increased macroeconomic uncertainties and major changes in the operating environment of power companies. The structure and arrangement of the asset face difficulties. The energy industry will have a key part in achieving the 
cleansing objective of developing the system. These objectives will include structural optimization, autonomously innovating, constructing an open system for innovative technologies, sustaining energy savings and emission reductions, and setting up a low-carbon mode.

On the other hand, scholars have done a lot of research on the relationship between social network structural characteristics and innovation performance. The research on social network structural characteristics mostly focuses on the relationship between single structural characteristics and innovation performance. The function of interconnection, the function of knowledge transfer, and the strength of the connection between innovation themes are all very critical factors. The main reasons are the lack of integrated viewpoints, the lack of measurement of many factors, and the impact of innovation performance. In addition, the existing research mostly focuses on the performance of enterprise innovation and infrequently integrates enterprise technological innovation. The growth of economic, ecological, and social systems, as well as a lack of attention to the continued ability of industry technological efficiency and consequences, has certain restrictions. The performance of green innovation is to combine the collaborative power of production, learning, and research of the innovation subject. It reduces the negative impact of power enterprises on the ecological environment through technology, management, and green innovation concept. It can comprehensively improve the resource utilization efficiency of power enterprises and realize the transformation of green development and industrialization.

The volume of such information has also been raised with energy taken on Big Data, as a result of increasingly open phases such as the network structures and complex network analysis methods from which information may be obtained. In this research, we presented a methodology for the proximity factor of the innovation subject on green innovation performance. We examine the effects of technical and institutional closeness on the power industry from the perspective of the contiguity features of the innovation problem. We also used the additional performance of innovation agents, measured the complimentary link between surrounding networks, and advanced examination schemes. Additionally, the results of the research can give a theoretical basis and policy reference for Chinese power sector innovation in the field of collaborative optimization. Based on the facts of a green patent in the electricity business, energy conservation and environmental protection, technical innovation, and trade reforms in respect of energy rights and intellectual property rights are, respectively, the basis.

The rest of the paper is organized as follows. In Section 2, a proposed system related work is outlined. The measurement model and variables process analysis is conducted in Section 3. The experimental results and discussion is further summarized in Section 4. Finally, Section 5 concludes the paper with a summary and future research directions.

\section{Related Work}

2.1. Green Innovation Performance. The study on the impact and mechanism of the green innovation performance on companies is distinct for most researchers in Germany and overseas from that of traditional innovation performance on companies. Scott [1] thinks, for instance, that corporations must also consider demand-side issues in addition to typical R\&D operations. These include market demand, environmental guidelines, and pressure on business innovation performance in the same industry. Jin et al. [2] believe that compared with traditional innovation performance, green innovation performance has an important impact on the internal operations of enterprises in terms of reducing resource search costs. Meng and $\mathrm{Fu}$ [3] believe that the comprehensive pollution index and carbon emission should be introduced into the performance evaluation system of green innovation in enterprises as nonexpected output.

2.2. Multidimensional Proximity. In the Western theoretical circles, the French Proximity Dynamics School was the first to study multidimensional proximity and established a framework of multidimensional proximity by standardizing the research paradigm of the new economic space. Among them, Kirat and Lung [4] introduced geographic, organizational, and institutional proximity into the multidimensional proximity framework. Rallet and Torre [5] focus not only on geographic proximity but also on the proximity of affiliation and similarity. After that, other scholars supplemented the proximity framework based on the above three dimensions. Knoben and Oerlemans [6] extended the seven dimensions of cognition, culture, technology, and social proximity. These author analyze the relevant theoretical and empirical research results of Western scholars and focus on the role of geographical proximity, technology proximity, and institutional proximity of innovation subjects in green innovation performance [7-10].

A company's social network is the key to green innovation performance. The examination of the components that generate the green innovation performance of the organization can be split into two elements based on the network background: institutional environment and limitation of resources. The mechanism of the closeness of innovation bodies in the network environment to green innovation performance is therefore particularly crucial to investigate. The present data nevertheless reveal that less study is being carried out on the green innovation performance of innovation topics based on proximity features, notably in the power business [11].

\subsection{The Impact of Geographic Proximity on Green Innovation} Performance. Geographic proximity is also called physical proximity, which plays an important role in explaining knowledge spillovers and exchanges among innovation subjects, compared with other proximity. The influence of geographic proximity on the innovation cooperation network is mainly reflected in three aspects. First, from the perspective of knowledge spillover, geographic proximity can enhance organizational learning and innovation behavior caused by knowledge flow, especially the flow of tacit knowledge. Cao and Chang-Jiang [12] believe that geographical proximity promotes the exchange of invisible 
knowledge, causes the knowledge spillover reduction effect, promotes the collision of innovative consciousness and ideas to a certain extent, enables innovation entities to develop more innovative products, and continuously consolidates and enhances its center of mind in the network. Second, from the perspective of the mobility of organizational resources, the smaller the geographical proximity is, the more conducive it is to the realization of technology transfer and provides more information consultation and invisible transfer knowledge for universities, research institutes, enterprises, and government parties; meanwhile, more knowledge spillovers are obtained, and the development ability of network members is improved (Torre and Gilly) [13]. Third, from the perspective of cost, companies in geographical proximity can form a common labor market, and geographical proximity reduces the potential for companies to use relational and structural inlays to obtain external knowledge (Ying et al.) $[14,15]$.

\subsection{The Impact of Technological Proximity on Green} Innovation Performance. The definition of technological proximity is based on the concept of technological distance proposed by Jaffe [16], which indicates the degree of technological similarity between the two places. The technological proximity in the innovation network is the degree of similarity in technological experience and absorptive capacity among innovation subjects (Yu and Sheng-Feng) [17]. From the perspective of resource allocation, when the technological basis of the innovation subject is low, it is difficult to transfer and absorb tacit knowledge, which is not conducive to collaborative innovation. With the similarity of the technological environment, the interactive communication, absorption, and innovation of all parties in the organization will be smoother, and the organizational interaction process will become easier and more efficient. A similar technological environment reduces the communication cost between innovation subjects and improves the efficiency of technology transfer [18-20].

\subsection{The Impact of Institutional Proximity on Green Innovation} Performance. The Chinese scholars' understanding of institutional proximity is based on North's understanding of the system, which is reflected in the similarity between the formal system and the informal system in the country or region in a broad sense. From the narrow sense, it is reflected in the consistency of behavior, norms, and thinking patterns among members of innovation organizations. The influence of institutional proximity on the innovation cooperation network is mainly reflected in three aspects [21]. First, from the perspective of cost, similar institutional constraints promote mutual imitation and learning among innovative subjects, glue the actions of innovative organizations together to form more stable psychological expectations, reduce the uncertainty of organizational communication, reduce its communication costs and transaction costs (Lagendijk and Lorentzen) [22], and avoid key knowledge leakage, and reduce instability. Second, from the perspective of the innovation system, institutional proximity provides a stable cooperation environment and system guarantee for cooperative innovation among innovation subjects. Tacit knowledge spreads smoothly among innovation partners, which is more conducive to the innovation subject to master market demand, industry status and basic theory, and cooperation background within the technical domain. A good internal and external environment is beneficial for enterprises to supplement and improve the existing knowledge reserve and provide the basis for sustainable green innovation performance selection (Zhou et al.) [23]. For the proximity of informal institutions, the cooperation between innovation subjects is not an occasional behavior, but a continuous transaction process. The organizational reputation and reputation in cooperation are important resources of the organization, which will become the transaction value of both parties of the organization, and have an important impact on the innovation performance in the next step. In general, most scholars believe that institutional proximity can promote the innovation performance of cooperating entities, but some scholars believe that institutional proximity can easily cause excessive knowledge spillover, which means the homogeneity of knowledge structure, and thus affects the emergence of new knowledge combinations (Xia et al.) [24-30].

\section{Measurement Model and Variables}

3.1. Measurement Model. Because the patent data jointly used by power companies and scientific research institutions is nonnegative and the integer is too large, it belongs to a different variable count data. While this article addresses choosing Poisson's regression and negativity of the binomial regression of the modeling analysis variable, the regression of Poisson is confined to equally distributed expectations and variances [31,32]. The overdiscretion of data can be resolved by negative bilateral regression. It is proven to be successful in analyzing the effects of factors on patentnonnegative discrete data (Liu et al.) [33] on the negative binomial regression model.

Thus, the research analyses the effects of multidimensional innovation proximities on green innovation performance in the power industry using the negative binomial regression model. The pattern is as follows:

$$
\begin{aligned}
\text { Patent }_{i j}= & \exp \left(\beta_{0}+\beta_{1} \mathrm{GP}_{i j}+\beta_{2} \mathrm{TP}_{i j}+\beta_{3} \mathrm{IP}_{i j}\right. \\
& +\beta_{4} \mathrm{GP}_{i j} \mathrm{TP}_{i j}+\beta_{5} \mathrm{TP}_{i j} \mathrm{IP}_{i j}+\beta_{6} \mathrm{GP}_{i j} \mathrm{IP}_{i j} \\
& +\beta_{7} \mathrm{IP}_{i j} * \mathrm{GP}_{i j} * \mathrm{TP}_{i j}+\beta_{8} \mathrm{OA}_{i j}+\beta_{9} \mathrm{OC}_{i j} \\
& \left.+\beta_{10} \mathrm{PS}_{i j}+\beta_{11} \mathrm{CC}_{i j}+\beta_{12} \mathrm{SHs}_{i j}+\eta_{i j}+\varepsilon_{i j t}\right) .
\end{aligned}
$$

Included are the green cooperative patents on invention between subject-matter I and topic $j$ and the green patent on innovation_patent online $j=n$ ( $n$ is an integer greater than $0)$. Variable of explanation GP represents geographical proximity, TP denotes proximity in technology, IP denotes institutional closeness, variable control $\mathrm{OA}$ is the age of the 
organization, OC is the organizational level, PS is an inventory for the organization of the patent in the last five years, CC is the coefficient of network agglomeration, and $\mathrm{SH}$ is the network indicator of the structural hole-limiting index [34-37].

3.2. Variable Setting. It can be seen from the existing research that the evaluation indicators of green innovation performance can be divided into two categories. One is inclined to constructing a composite index evaluation system to study green innovation performance. From the perspective of green innovation, Chen and Qian [38] believe that green innovation performance includes green $R \& D$ performance, manufacturing performance, and marketing performance. The performance of green $\mathrm{R} \& \mathrm{D}$ is reflected in the number of green patents granted and the conversion rate of green scientific and technological achievements. Li-Wen and Ji-Li [39] define green innovation performance as three dimensions of economic, environmental, and social performance from the perspective of input and output. Cheng and Shiu [40] constructed a green innovation performance evaluation system from the three dimensions of green organization, green technology, and green products [41, 42].

Considering the effect of multidimensional proximity on the green innovation performance of innovation subjects and the operability of actual measurement, three proximity indicators of geography, technology, and system are selected as the main factors for analyzing the formation of interorganizational innovation networks. Refer to the measurement methods of Balland [43] and Jaffe, etc.; use the technical structure vector to calculate the technical proximity, as shown in equation (2). Among them, $f_{i}=\left[n_{1}, n_{2}\right.$, $\left.\ldots, n_{k}\right], n_{k}$ means that enterprise $i$ owns in the technical field $k$. The numbers of patents, $f_{i}$ and $f_{j}$, are the technical structure vectors of enterprises $i$ and $j$, respectively, which are composed of the number of patents owned by enterprises $i$ and $j$ in different technical fields, respectively. The value of $P_{i j}$ is between 0 and 1 . The closer it is to 0 , the lower the technical similarity of the two parties in the innovation is, and the closer it is to 1 , the more similar the technical structure of the two parties in the innovation is:

$$
P_{i j}=\frac{f_{i} f_{j}^{\prime}}{\left[\left(f_{i} f_{j}^{\prime}\right)\left(f_{i} f f_{j}^{\prime}\right)\right]^{1 / 2}} .
$$

The geographic proximity measurement method firstly obtains the geographic distance between two actors according to the geographic longitude and latitude coordinates of the city where the actors are located:

$$
D_{i j}=6371 *\left\{\arccos \left[\sin \left(\operatorname{lat}_{i}\right) \sin \left(\operatorname{lat}_{j}\right)+\cos \left(\operatorname{lat}_{i}\right) \cos \left(\operatorname{lat}_{j}\right) \cos \left(\left|\operatorname{long}_{i}-\operatorname{long}_{j}\right|\right)\right]\right\} .
$$

Among them, $D_{i j}$ is the geographic distance between the innovation agent $i$ and the innovation agent $j$, and lat and long are the latitude and longitude of the innovation agent, respectively. Second, calculate the geographical proximity index value according to the following equation:

$$
\text { Geoprox }=\frac{\operatorname{MAXD}_{i j}-D_{i j}}{\operatorname{MAXD}_{i j}-\operatorname{MIND}_{i j}} .
$$

The value of the geographical proximity index is between 0 and 1 . The closer to it is 1 , the higher the geographical proximity between innovative entities and the smaller the geographical distance are, and vice versa. According to the structural whole index given by Burt, the structural hole needs to consider the effective size, efficiency, constraint, and hierarchy. This complex relationship is the basis of cooperation between innovative organizations (Burt) [44]. This article selects the degree of restriction, that is, the ability of the innovation subject to use structural holes in the innovation network as a control variable. The degree of restriction is the most important indicator in the structural whole index. Burt points out that the limit of the opportunity of the main body in the innovation network depends on the input intensity of the innovation subject with important relationship to the third-party relationship (Burt) [44]. The expression is as follows:

$$
C_{i j}=\left(p_{i j}+\sum_{q} p_{i q} p_{q j}\right)^{2} .
$$

$P_{i j}$ is the ratio of the relationship invested in $j$ to the total number of relationships among all the relationships of the actor $i$. The smaller the limit index is, the more open the covered network is and the more structural holes there are. The average local density is mainly reflected in the innovation network. The clustering coefficient measures the degree of local group in which nodes tend to gather together, that is, the average number of neighbor pairs between the $k_{i}$ neighbors of all nodes in the network, and the expression is $C=\sum_{i=1}^{N} C_{i} / N$, where $n$ is the number of nodes in the network, $C_{i}=2 E_{i} / k_{i}\left(k_{i}-1\right)$, where $E_{i}$ is $k$ of node $i$. The number of edges that actually exist between $i$ adjacent nodes is $j$. Since all dependent variables and independent variables in this article are binary data, all control variables are also binarized. Take the patent stock as an example, as in the following equation, the other control variables are processed in the same way as the patent stock [45-48]. 


$$
\mathrm{PS}_{i j}=\ln \left[1+\frac{\left(\mathrm{PS}_{i}+\mathrm{PS}_{j}\right)}{2}\right] .
$$

\section{Results and Discussion}

4.1. Data Source. In this article, we retrieve the dataset from January 2, 2021, and the patent application date (explained variable) is from January 1, 2016, to December 31, 2020. To reflect the characteristics of interdisciplinary and technological integration, project searches are all invention patent researches jointly applied. The method is to input the combination of university, college, research institute, company, group, and enterprise in the search column of the patent applicant (patent right) in the database. A total of 2,2015 invention patents were retrieved [49]. Through data cleaning, the data in the search results that do not meet the requirements of a joint application for invention patents are discarded. Since the amount of data containing three or more patent applicants is relatively small, it facilitates research. Taking the system neighboring cooperative network layer as an example, the nodes and connecting edges generated by Gephi are shown in Figure 1, which shows the cooperative patent application between applicants in the network.

The network node scale is $N=453$, with network edges number $E=984$. The top two organizations, the State Grid Corporation of China (N2) and the China Electric Power Research Institute Co., Ltd. (N5), have an index rate of 36,784 and 32,455 , respectively, and have links in the innovation network with almost 30 companies on an average. The amount of structural constraints, 0.034 and 0.047 , is quite minimal, showing that the two primary organizations are more likely than intermediaries to have direct communication.

4.2. Statistics and Correlation Analysis. This article utilizes Stata 15 for descriptive statistics and variable correlation analyses. Table 1 provides each variable's correlation coefficient matrix including medium, minimum, maximum, standard deviation, and inflation factor of variance (VIF). Table 1 shows the results.

As shown in Table 1, the correlation between technological proximity and geographic proximity and institutional proximity is low, respectively, $-0.1119,-0.0524$, and 0.2615 , indicating that the explanatory variables are suitable for analyzing interaction effects. The average value of green innovation performance is 2.7198 , the variance is 48.4275 , which is much larger than the mean. The green innovation performance is a counted nonnegative integer, which is suitable for analysis using negative binomial regression model. In addition, the variance inflation factor (VIF) of this paper is less than 3 , and the average VIF is 1.64 , indicating that there is no multilinearity problem among the variables, and it can be incorporated into the regression equation for regression analysis. Table 2 shows the results of negative binomial regression.

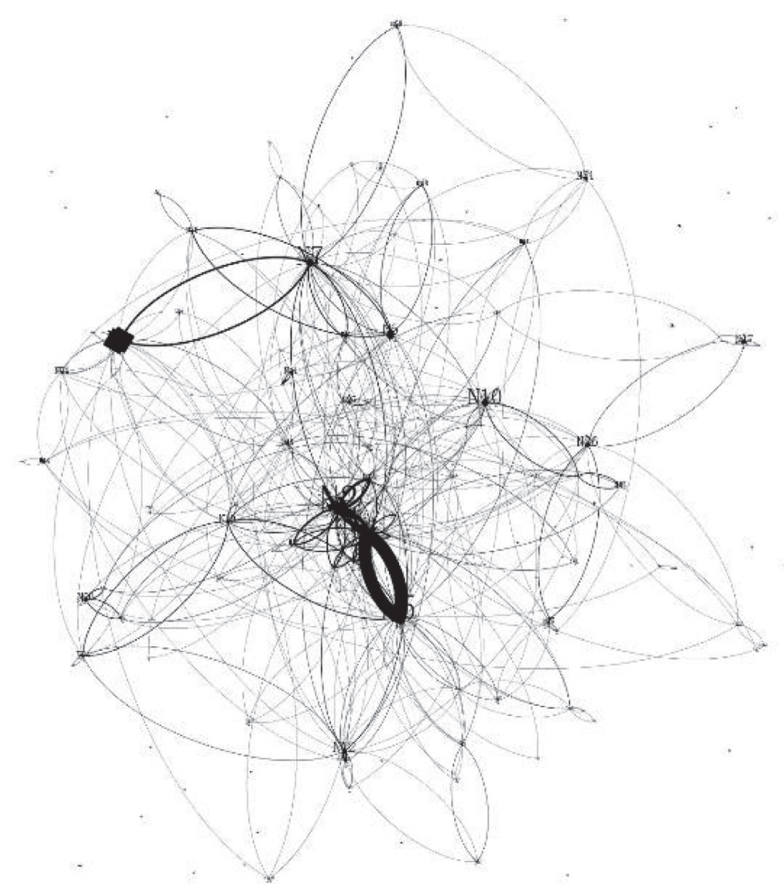

FIGURE 1: The green innovation performance cooperation network architecture diagram.

(1) The connection between control and green innovation performance is tested in Model 1. Basically, in different models, the impact of these control variables is the same. The concentration coefficient, the entire network, the organizational level, and the age of the organization are the same. The connection between the achievements of green innovation is important. The agglomeration of the network is strongly connected to the performance of green innovation $(\beta=3,1319, p<0,0.05)$.

(2) The retrenching factor of Model 2 at 1 percent $(\beta=1.0444, p<0.01)$ is positive and significant. It demonstrates that the geographical distance between topics of innovation significantly contributes to the performance of the green innovation sector, and it confirmed the $\mathrm{H} 1$ hypothesis.

(3) The regression coefficient of Model 3 is positive at 5 percent $(\beta=2.8178, \quad p<0.05)$ and suggests that technical distance between subjects of innovation plays an important role in fostering green innovation efficiency in the electricity business.

(4) Model 4 has a positive and significant regression coefficient of 1 percent $(\beta=0.6221, p<0.01)$. It demonstrates a considerable promotional influence on the performance of the green energy innovation business, as shown by the institutional distance between innovation subjects and $\mathrm{H} 3$.

(5) Model 5 findings suggest that the interaction coefficients of geographic proximity and technology proximity at $1 \%(\beta=0.9058, p<0.01)$ are positive and significant. 
TABle 1: Descriptive statistics and correlation analysis.

\begin{tabular}{|c|c|c|c|c|c|c|c|c|c|}
\hline & Patents & GP & $\mathrm{TP}$ & IP & $\mathrm{OA}$ & OC & PS & $\mathrm{CC}$ & SHs \\
\hline Patents & 1 & & & & & & & & \\
\hline GP & 0.0578 & 1 & & & & & & & \\
\hline $\mathrm{TP}$ & 0.1008 & -0.1119 & 1 & & & & & & \\
\hline IP & 0.1733 & -0.0524 & 0.2615 & 1 & & & & & \\
\hline $\mathrm{OA}$ & -0.1242 & -0.0136 & -0.1344 & -0.6492 & 1 & & & & \\
\hline $\mathrm{OC}$ & 0.2511 & -0.1765 & 0.1976 & 0.0826 & 0.0559 & 1 & & & \\
\hline PS & 0.0927 & -0.1223 & 0.0847 & 0.0761 & -0.0221 & 0.5529 & 1 & & \\
\hline $\mathrm{CC}$ & 0.0881 & -0.1122 & -0.0321 & 0.1481 & -0.1171 & 0.0309 & 0.0359 & 1 & \\
\hline SHs & -0.1513 & 0.2713 & -0.3956 & -0.0005 & -0.1919 & -0.4551 & -0.3113 & -0.167 & 1 \\
\hline Mean & 2.7198 & 0.78627 & 0.8261 & 0.3844 & 3.3940 & 7.5968 & 6.8829 & 0.0153 & 0.3735 \\
\hline Min & 1 & 0.0106 & 0.0078 & 0 & 1.3862 & 3.8286 & 0 & 0 & 0.0397 \\
\hline Max & 113 & 1 & 1 & 1 & 4.5643 & 10.0255 & 10.2808 & 0.2874 & 0.6931 \\
\hline SD & 6.9589 & 0.2296 & 0.2032 & 0.4869 & 0.6671 & 1.3035 & 2.0974 & 0.0343 & 0.1851 \\
\hline Var & 48.4275 & 0.0528 & 0.0413 & 0.2371 & 0.4451 & 1.6992 & 4.3993 & 0.0012 & 0.0343 \\
\hline VIF & - & 1.09 & 1.35 & 2.01 & 1.98 & 1.83 & 1.86 & 1.09 & 1.88 \\
\hline
\end{tabular}

TABle 2: Negative binomial regression analysis.

\begin{tabular}{|c|c|c|c|c|c|c|c|c|}
\hline & $(1)$ & $(2)$ & (3) & $(4)$ & $(5)$ & $(6)$ & $(7)$ & $(8)$ \\
\hline $\mathrm{OA}$ & $\begin{array}{c}-0.5971^{* * *} \\
\quad(4.99)\end{array}$ & $\begin{array}{c}-0.5852^{* * *} \\
\quad(5.56)\end{array}$ & $\begin{array}{c}-0.5375^{* * *} \\
\quad(5.48)\end{array}$ & $\begin{array}{c}-0.3093^{* * *} \\
(2.69)\end{array}$ & $\begin{array}{c}-0.5361^{* * *} \\
\quad(5.68)\end{array}$ & $\begin{array}{c}-0.2631^{* * *} \\
\quad(2.73)\end{array}$ & $\begin{array}{c}-0.3009^{* * *} \\
(2.70)\end{array}$ & $\begin{array}{c}-0.2569^{* * *} \\
(2.64)\end{array}$ \\
\hline $\mathrm{OC}$ & $\begin{array}{c}0.2911^{* * *} \\
(3.91)\end{array}$ & $\begin{array}{c}0.2846^{* * *} \\
(4.17)\end{array}$ & $\begin{array}{c}0.2810^{* * *} \\
(3.90)\end{array}$ & $\begin{array}{c}0.2761^{* * *} \\
(3.95)\end{array}$ & $\begin{array}{c}0.2818^{* * *} \\
(4.16)\end{array}$ & $\begin{array}{c}0.2778^{* * *} \\
(4.35)\end{array}$ & $\begin{array}{c}0.2656^{* * *} \\
(3.81)\end{array}$ & $\begin{array}{c}0.2655^{* * *} \\
(4.18)\end{array}$ \\
\hline PS & $\begin{array}{c}-0.0065 \\
(-0.15)\end{array}$ & $\begin{array}{c}-0.0046 \\
(-0.12)\end{array}$ & $0.0018(0.04)$ & $0.0303(0.68)$ & $0.0042(0.11)$ & $0.0400(0.98)$ & $0.0314(0.71)$ & $0.0421(1.04)$ \\
\hline $\mathrm{CC}$ & $\begin{array}{c}3.1319^{* * * *} \\
(2.12)\end{array}$ & $\begin{array}{c}3.3525^{* * * *} \\
(2.56)\end{array}$ & $\begin{array}{c}3.6564^{* * *} \\
(2.35)\end{array}$ & $2.4106^{*}(1.75)$ & $\begin{array}{c}3.8253^{* * *} \\
(2.61)\end{array}$ & $\begin{array}{c}2.4559^{* * * *} \\
(2.08)\end{array}$ & $3.0135^{* *}(2.11)$ & $\begin{array}{c}3.0508^{* * * *} \\
(2.37)\end{array}$ \\
\hline SHs & $\begin{array}{c}-0.8709^{* * *} \\
(-2.29)\end{array}$ & $\begin{array}{c}-1.1803^{* * *} \\
(-3.13)\end{array}$ & $\begin{array}{c}-0.6549 \\
(-1.42)\end{array}$ & $\begin{array}{c}-0.5960^{*} \\
(-1.65)\end{array}$ & $\begin{array}{c}-0.7211^{* *} \\
(-2.07)\end{array}$ & $\begin{array}{c}-0.5818^{*} \\
(-1.81)\end{array}$ & $\begin{array}{c}-0.5344 \\
(-1.47)\end{array}$ & $\begin{array}{c}-0.5133 \\
(-1.60)\end{array}$ \\
\hline
\end{tabular}

(6) Model 6 findings suggest that geographical closeness and institutional closeness coefficients of interaction are positive and at $1 \%(\beta=0.9253, p<0.01)$, they are significant.

(7) Model 7 findings suggest that at $1 \%(\beta=0.6771$, $p<0.01)$ the technical closeness coefficient and institutional interaction duration are positive and significant.

(8) Model 8 findings suggest that the interaction coefficient between geography and technical closeness and institutional closeness; at 1 percent $(\beta=0.9938$, $p<0.01$ ), it is positive.

There is a complementary and important interplay between geographical proximity, technical closeness, and institutional closeness. They can only contribute an ongoing drive to technological progress if they are closely interrelated. Table 2 shows negative binomial regression analysis.

4.3. Big Data Heterogeneity Analysis. Furthermore, we perform the robustness test in this paper by taking the logarithm for the number of dependent variable green collaborative patent applications and use negative binomial regression tests to determine how the institutional proximity directly affects the green innovation performance of the energy sector to test the robust nature of the institutional proximity to the green innovation. In comparison with Model 4's negative binomial regression findings in Figure 2, the signs of the regressive coefficients are still the same and the meaning shift from a confidence interval of 99 percent to a confidence interval of 95 percent. Institutional closeness has the strength of the green innovation mechanism.

The article begins with the intensity of environmental restraint and economic development policies of the regions of innovation subjects and uses the grouping method of regression in order to examine the difference in the performance level of green innovation of energy sector subjects in multidimensional proximity. The multidimensional closeness to the green innovation performance of innovation topics in the power industry is positive or inverted based on regression analysis and the stability test. However, the economic situation and the strength of environmental restriction measures vary in various places. Innovative topics may also affect the performance of green innovation. To further explore the mechanism of multidimensional 


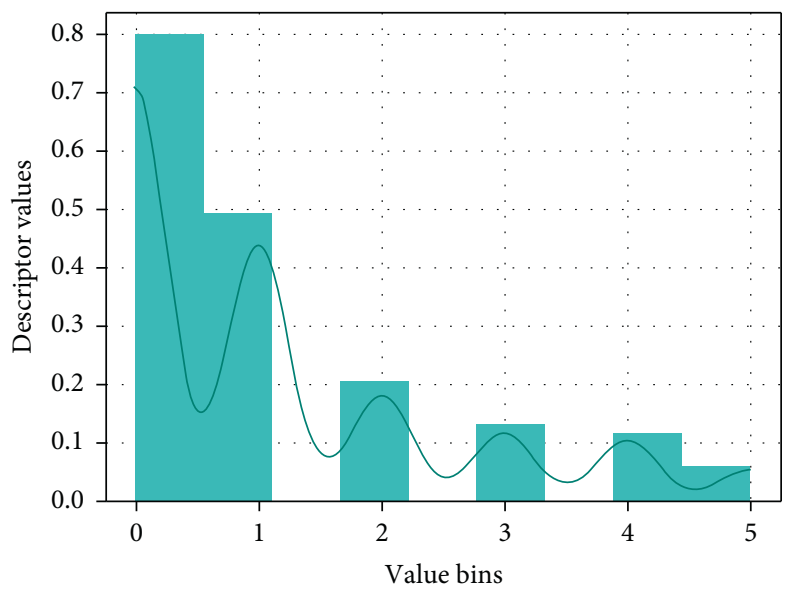

— Category 1

FIGURE 2: Robustness test results.

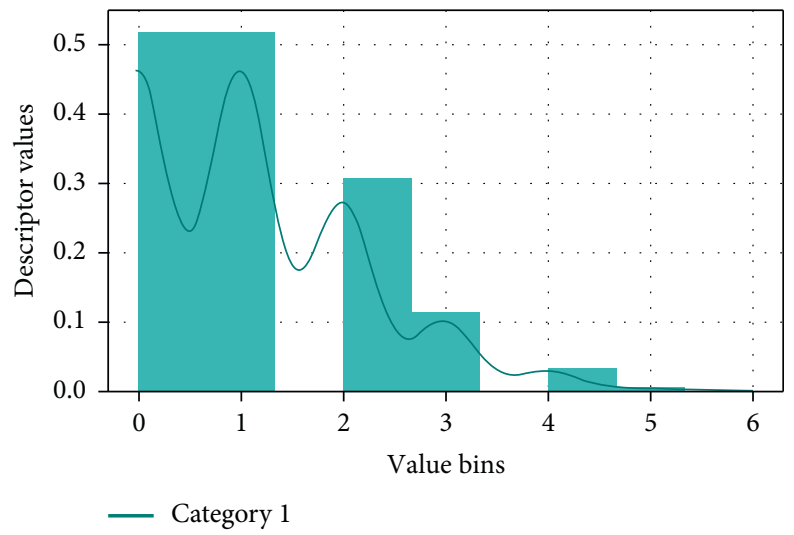

Figure 3: Tests of the heterogeneity of the intensity of environmental restraint policies.

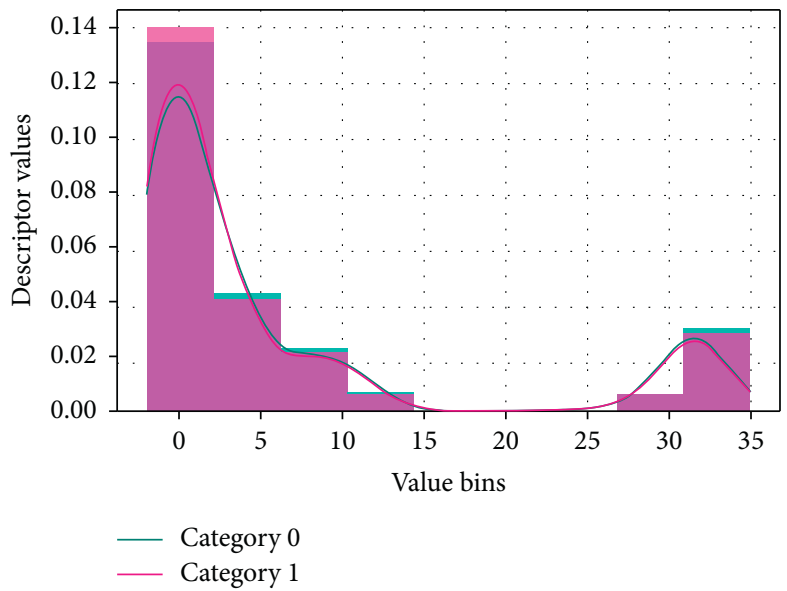

FIGURE 4: Test of heterogeneity of regional economic development intensity. 
proximity on the degree of performance of green innovation in power industries, tests of the heterogeneity of the intensity of environmental restraint policies are shown in Figure 3.

Finally, the performance of green innovation in the underdeveloped areas is significantly lower than that of the developed regions. Test of the heterogeneity of regional economic development intensity is shown in Figure 4.

\section{Conclusion}

Based on the perspective of multidimensional proximity, this paper relies on Gephi, Ucinet, and Stata analysis software. We use a negative binomial regression model to theoretically analyze the impact of geographic, technologi$\mathrm{cal}$, and institutional proximity on green innovation performance. Firstly, we have a stronger influence on green innovation performance of power industry innovation businesses compared with geographical closeness and institutional closeness. Secondly, the direction and importance of the key variables have not altered considerably by utilizing alternative data to assess the stability test for geographical proxy, technical closeness, and institutional closeness. Thirdly, environmental policy restrictions will impact the link between multidimensional proximity and green innovation performance of the innovation business. Finally, a degree of economic growth affects the link between multidimensional closeness and green innovation success in the power industry. More important is the association between multidimensional closeness and green innovation among topics in the developed areas.

\section{Data Availability}

The datasets used and/or analyzed during the current study are available from the corresponding author upon reasonable request.

\section{Conflicts of Interest}

All authors of this article declare no conflicts of interest.

\section{References}

[1] M. Hujala, A. Knutas, T. Hynninen, and H. Arminen, "Improving the quality of teaching by utilising written student feedback: A streamlined process," Computers \& Education, vol. 157, Article ID 103965, 2003.

[2] C. Jin, L. Liang, and $\mathrm{H}$. Wu, "Industrial agglomeration and innovation performance under the background of open innovation: evidence from Chinese high-tech industries," Studies in Science of Science, vol. 31, no. 4, pp. 623-629, 2013.

[3] W.-D. Meng and B. Fu, "Research on regional agglomeration and spatial heterogeneity of green innovation performance," Statistical Observation, vol. 16, no. 23, pp. 94-97, 2017.

[4] T. Kirat and Y. Lung, "Innovation and proximity," European Urban and Regional Studies, vol. 6, no. 1, pp. 27-38, 1999.

[5] A. Rallet and A. Torre, "Is geographical proximity necessary in the innovation networks in the era of global economy," GeoJournal, vol. 49, no. 4, pp. 373-380, 1999.

[6] J. Knoben and L. A. G. Oerlemans, "Proximity and interorganizational collaboration: a literature review,"
International Journal of Management Reviews, vol. 8, no. 2, pp. 71-89, 2006.

[7] M. Wagner, "On the relationship between environmental management, environmental innovation and patenting: evidence from German manufacturing firms," Research Policy, vol. 36, no. 10, pp. 1587-1602, 2007.

[8] J. Li and Z.-Y. Chen, "Institutional advantage transfer:political connection and business green innovation," Science of Finance and Economics, vol. 9, pp. 108-118, 2020.

[9] Y. Zhou, J. Hong, K. Zhu, Y. Yang, and D. Zhao, "Dynamic capability matters: uncovering its fundamental role in decision making of environmental innovation," Journal of Cleaner Production, vol. 177, no. 5, pp. 516-526, 2018.

[10] A. Rezaeipanah, S. S. Matoori, and G. Ahmadi, "A hybrid algorithm for the university course timetabling problem using the improved parallel genetic algorithm and local search," Applied Intelligence, vol. 51, no. 1, pp. 467-492, 2020.

[11] Y. Xu, F. Jiang, J. Du, and D. Gong, “A cross-domain collaborative filtering algorithm with expanding user and item features via the latent factor space of auxiliary domains," Pattern Recognition, vol. 94, pp. 96-109, 2019.

[12] X. Cao and S. Chang-Jiang, "Green innovation behavior among housing developers: impact of portfolio depth and scope," China Soft Science, vol. 4, pp. 120-131, 2017.

[13] A. Torre and J. P. Gilly, "On the analytical dimension of proximity dynamics," Regional Studies, vol. 34, no. 2, pp. 169-180, 2000.

[14] H.-B. Ying and Y.-S. Zhang, S.-F. Chen, "An empirical study on the influence of network mosaic and geographical proximity on enterprise knowledge acquisition," Science \& Technology Progress and Policy, vol. 32, no. 9, pp. 132-135, 2015.

[15] W. Jiang, Y. Ying, and L. Yang, "R \& D geographic dispersion, technology diversity, and innovation performance," Studies in Science of Science, vol. 31, no. 5, pp. 772-779, 2013.

[16] A. B. Jaffe, "Technological opportunity and spillovers of R \& D :evidence from firms' patents, profits and market value," American Economic Review, vol. 76, no. 5, p. 984, 1986.

[17] Y.-D. Yu and Y. Sheng-Feng, "Proximity and evolution of independent collaboration innovation network: evidence from IC industry chain," Science \& Technology Progress and Policy, vol. 34, no. 14, pp. 66-76, 2017.

[18] Y. Bo-Xu, Y.-R. Wang, and L. Xing-Guang, "The impact of multi- dimensional proximity on cooperative innovation," Studies in Science of Science, vol. 37, no. 1, pp. 154-164, 2019.

[19] Y. Xu, Y. Chu, F. Jiang, Y. Guo, and D. Gong, "SVMs classification based two-side cross domain collaborative filtering by inferring intrinsic user and item features," KnowledgeBased Systems, vol. 141, pp. 80-91, 2018.

[20] C. Lin, Y. J. Wu, and C. C. Chang, "The alliance innovation performance R \& D alliances: the absorptive capacity perspective," Technovation, vol. 32, no. 3, pp. 282-292, 2016.

[21] F. Shi, Y. Gao, S.-B. Chen, and X. Cai, "Technological distance, geographical distance and university-enterprise synergetic innovation," -Chinese Journal of Management, vol. 13, no. 11, pp. 1665-1673, 2016.

[22] A. Lagendijk and A. Lorentzen, "Proximity, knowledge and innovation in peripheral regions. on the intersection between geographical and organizational proximity," European Planning Studies, vol. 15, no. 4, pp. 457-466, 2007.

[23] Q. Zhou, L. Hou, and M. Chong-Feng, "Research on the effect path of institutional proximity on cooperative innovation of high-tech enterprises," Science \& Technology Progress and Policy, vol. 30, no. 10, pp. 81-83, 2013. 
[24] L.-J. Xia, X. Fu-Ji, and H.-H. Wang, "The impact of institutional proximity and technological proximity on industryuniversity collaborative innovation performance: an analysis of joint-patent data," Studies in Science of Science, vol. 35, no. 5, pp. 782-791, 2017.

[25] C. Autant-Bernard, "The geography of knowledge spillovers and technological proximity," Economics of Innovation and New Technology, vol. 10, no. 4, pp. 273-254, 2001.

[26] Y. Xu, J. Yang, and Z. Xie, "Training SVMs on a bound vectors set based on fisher projection," Frontiers of Computer Science, vol. 8, no. 5, pp. 793-806, 2014.

[27] J. Singh, "Collaborative networks as determinants of knowledge diffusion patterns," Management Science, vol. 51, no. 5, pp. 756-770, 2010.

[28] Q.-X. Wang, "Inter-provincial knowledge spillovers under multiple dimensions of proximity: an empirical examination by spatial panel data analysis," Studies in Science of Science, vol. 31, no. 7, pp. 1068-1073, 2013.

[29] Y. Qian and B. Meng-Ping, "Does multi-dimensional proximity promote innovation cooperation between new energy automobile enterprises in China?" $R$ \& $D$ Management, vol. 30, no. 6, pp. 67-74, 2018.

[30] Y. Qin and G. Zeng, "Comparison of innovation networks of analytical and synthetic industries: an empirical analysis on China biomedicine and environmental protection industry," Economic Geography, vol. 38, no. 10, pp. 142-154, 2018.

[31] D. B. Audretsch and M. P. Feldman, "R \& D spillovers and the geography of innovation and production," American Economic Review, vol. 86, no. 3, pp. 630-640, 1996.

[32] Y.-R. Zhang, The Formation, Evolution and Effects of Innovation Network, Huazhong University of Science and Technology Press, Wuhan, China, 2019.

[33] X.-Y. Liu, L. Jin-Peng, S. Xiao-Hong, and J. Yang, "The influence of multidimensional proximity on patent technology transaction in integrated circuit industry," Studies in Science of Science, vol. 38, no. 5, pp. 834-842, 2020.

[34] X. Yu, D. Zhan, L. Liu, H. Lv, L. Xu, and J. Du, "A privacypreserving cross-domain healthcare wearables recommendation algorithm based on domain-dependent and domainindependent feature fusion," IEEE Journal of Biomedical and Health Informatics, vol. 5, 2021.

[35] Y. Qian and S.-H. Wang, "Cooperative innovation of strategic emerging industries within province under multi-dimensional proximity," Journal of Beijing University of Posts and Telecommunications (Social Sciences Edition), vol. 22, no. 6, pp. 41-51, 2020.

[36] P.-N. Ruan, W.-L. Wang, and L. Xiao-Yan, "Dynamic evolution of technological innovation network based on multidimensional proximity," $R$ \& $D$ Management, vol. 30, no. 6, pp. 59-66, 2018.

[37] H.-H. Wang, W. Meng-Yi, and Y.-J. Sun, "Study on influencing factors of cross-regional industry-university collaborative innovation performance in the perspective of social network," Science and Technology Management Research, vol. 39, no. 3, pp. 26-33, 2019.

[38] R.-L. Chen and L. Qian, "Establishment of corporate green performance evaluation system," Journal of Changchun University of Technology, vol. 41, no. 5, pp. 508-513, 2020.

[39] S. Li-Wen, C. Ji-Li, "Performance evaluation of green innovation based on EES coordinated development: taking bohai economic rim as an example," Science and Technology Management Research, vol. 2018, no. 8, pp. 87-93, 2018.
[40] C. C. Cheng and E. C. Shiu, "Validation of a proposed instrument for measuring eco-innovation: an implementation perspective," Technovation, vol. 32, no. 6, pp. 329-344, 2012.

[41] Y. Eiadat, A. Kelly, F. Roche, and H. Eyadat, "Green and competitive? an empirical test of the mediating role of environmental innovation strategy," Journal of World Business, vol. 43, no. 2, pp. 131-145, 2008.

[42] M. Yu, T. Quan, Q. Peng, X. Yu, and L. Liu, "A model-based collaborate filtering algorithm based on stacked AutoEncoder," Neural Computing and Applications, vol. 6, 2021.

[43] P.-A. Balland, "Proximity and the evolution of collaboration networks: evidence from research and development projects within the global navigation satellite system (GNSS) industry," Regional Studies, vol. 46, no. 6, pp. 741-756, 2012.

[44] R. S. Burt, Structural Holes: The Social Structure of Competition Cambridge, Harvard University Press, Cambridge, MA, USA, 1992.

[45] J. S. Coleman, "Social capital in the creation of human capital," American Journal of Sociology, vol. 1988, no. 94, pp. 95-120, 1988.

[46] R. S. Burt, "The contingent value of social capital," Administrative Science Quarterly, vol. 42, no. 2, pp. 339-365, 1997.

[47] L. Zhen-Qiang, "The impact of multidimensional proximity on innovation performance," Inner Mongolia Sciences, vol. 35, no. 4, pp. 104-108, 2019.

[48] S. Namibians, "Industry technical committees, technological distance, and innovation performance," Research Policy, vol. 42, no. 4, pp. 928-940, 2013.

[49] M. Yan-Yan, L. Feng-Chao, and S. Yu-Tao, "Research on Chinese university-enterprise cooperation networks of patent applications," Studies in Science of Science, vol. 29, no. 3, pp. 390-395, 2011. 